\title{
A Brief Discussion about the Aesthetic Perspective of Photographic Composition
}

\author{
Yang Zhi \\ Hunan University of Humanities, Science and Technology \\ Loudi, Hunan
}

\begin{abstract}
All kinds of artistic creation are greatly associated with composition. In the process of shooting, composition determines whether a work is a success or a failure. Photographic art is to create the formal aesthetic feeling based on aesthetics. In order to create a great work, one needs to use aesthetic theory and knowledge as much as possible. At the same time, the presentation of a fine work must compose from the perspective of aesthetics and show its artistic quality and value by exploring photography from the perspective of aesthetics. What reflected by photographic composition is the process of visual thinking. For composition of both traditional and modern photography, improving composition from the perspective of aesthetics is a long-term plan and a reflection of creative thinking. This paper first introduces the emergence and development of photographic aesthetics, then expounds the artistic features of photographic composition, and highlights the value of the overall structure of photographic composition.
\end{abstract}

Keywords-Photographic art; Composition; Aesthetic perspective

\section{AN OVERVIEW OF PHOTOGRAPHIC COMPOSITION}

What is photographic composition? What subject contents does it reflect? In fact, photographic composition is that photographers properly adjust the layout of the subject contents in a scene. All subjects of photography come from life, the photographers will search for more expressive and artistically infectious moments, which are always vivid. When recording scenes, photographers adjust the layout of a scene in an organized and reasonable way, highlighting the subject by the most unique art form. People often like explaining photographic composition with theories from painting. But the composition of a photo is not to express a picture technically. To create an excellent picture, like a documentary work, one must know photographic composition in advance, then he can sensitively find wonderful moments in his life. Therefore, photographic composition has its own principle and pace.

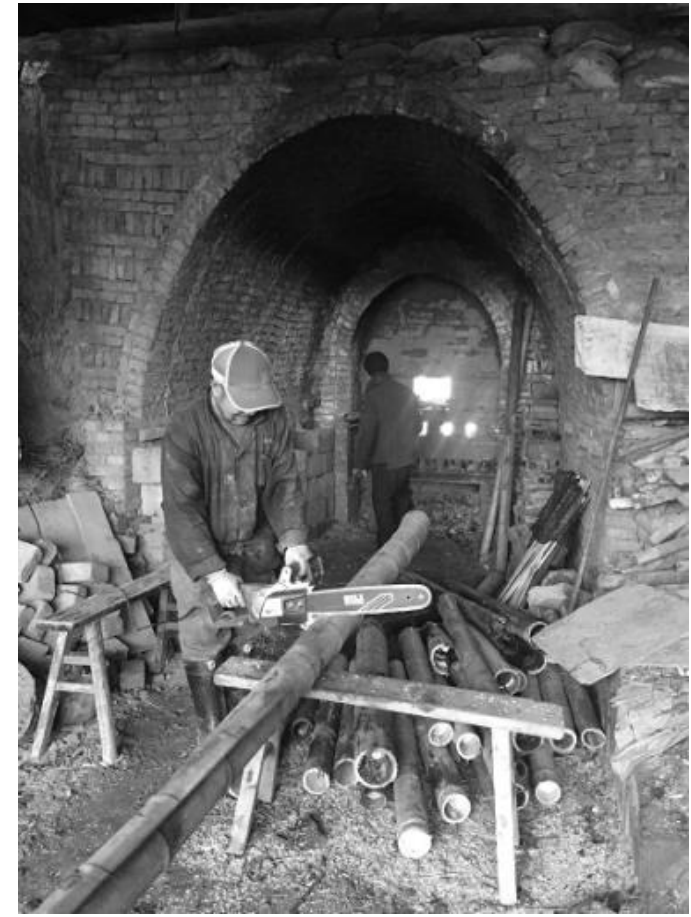

Fig. 1. Mortar makers are working

\section{THE EMERGENCE AND DEVELOPMENT OF THE} AESTHETIC PERSPECTIVE OF PHOTOGRAPHY

Photographic aesthetics is a branch of artistic aesthetics. With the invention of photography in 1839, photographic aesthetics was born. The earliest discussion on photographic aesthetics began when Louis-Jacques-Mandé Daguerre described the operation process and basic principle in The Factual History of the Evolution of Daguerreotype and Perspective Drawing. But since 1850s people began emphasizing on the aesthetic function of photography, which then reflected the cultural ambience of upper classes. When photography gradually went into ordinary people's life, photographic aesthetics found its way from old aesthetic consciousness of painting, which became the main guide for photography. Photographic aesthetics explores the aesthetic activities in photography through its unique regular pattern and explains the aesthetic features of photographic art, which extends and develops the aesthetic perspective of photography. 


\section{EXPLORATION FOR THE AESTHETIC PERSPECTIVE OF PHOTOGRAPHY}

\section{A. Organizational means of photographic composition}

When photographers need to best highlight the subjects in a scene, they will analyze the gradations in it and adjust the layout of it, whereby realizing the harmony of the elements in the scene. Photographic composition is reflected by the composing norms in photography. When objects are properly arranged as regard to perspective relationships and spacial organizational relationships as well as the organizational relationships of light and colors in the scene. To some extent, photographic composition also demonstrates more unique organizational forms

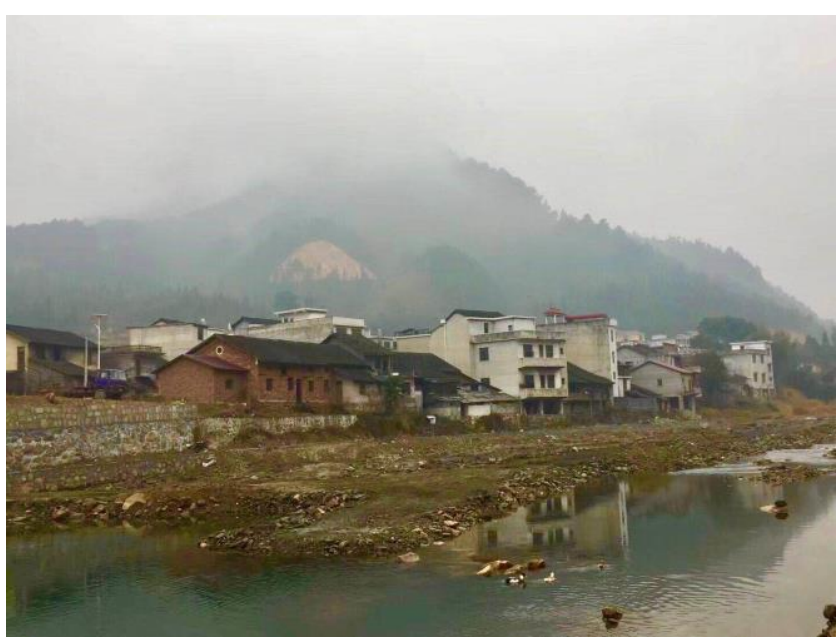

Fig. 2. Spring river warming duck prophet

\section{B. The manifestation of photographic composition}

The form of photographic composition is various. In 2-D and $3 \mathrm{D}$ scenes, there is the composition of dots, lines and surfaces. At the same time, from the perspective of formal beauty, composition can be divided into Sudoku, cross, triangle, trichotomy, S-shape, V-shape, C-shape and O-shape, etc. Among the above methods of composition, V-shape is the most variable one, which can be vertical, horizontal and upside down. It is relatively stable and able to highlight subjects.

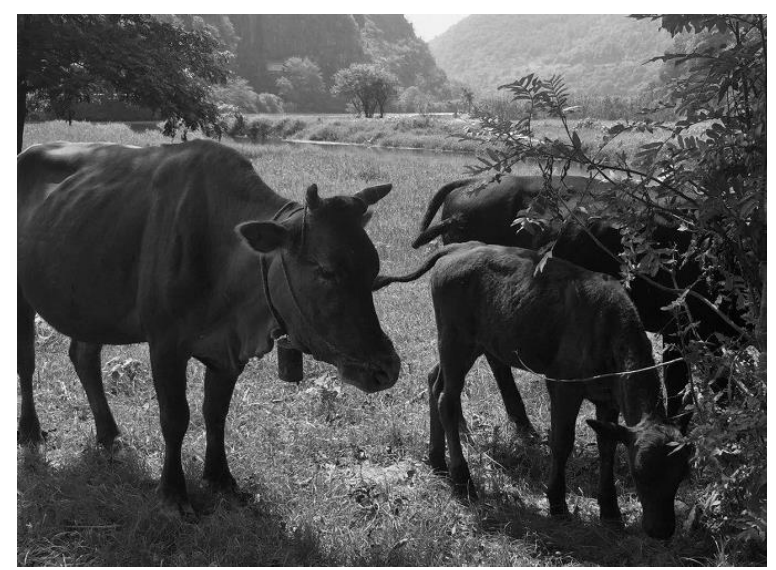

Fig. 3. Shot in Meijiang River Scenic Resort, Lianyuan

\section{Building people's aesthetics by means of photographic composition}

Photographic composition is one of the important means to express through photography. The reason that photographic art can be disseminated in the fast-paced life is that it can influence people's aesthetic consciousness. Only when photographic composition is unfolding, can it adjust the gradations and structure of a scene. To create a great work, one should compose from several perspectives rather a single perspective to enrich the manifestation of photography. Therefore, photographic composition can not only influence the ways to manifest of photography, it can also influence the expression of the subject. Besides, it can also shift the center of photography and make works more artistic, creating unexpected but reasonable effects.

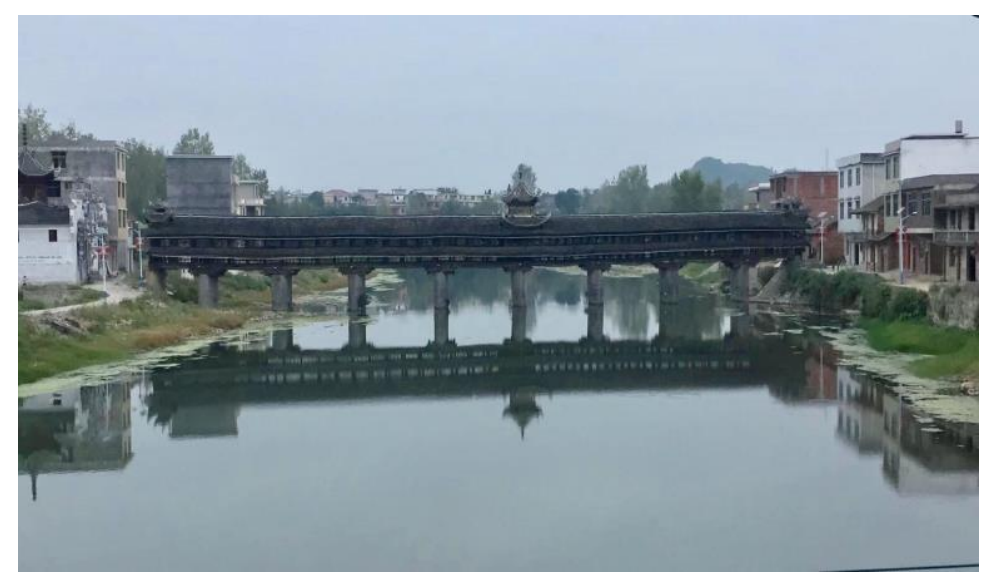

Fig. 4. Hometown

\section{Typicality and transience of photographic composition}

Our life is colorful and variable. New things happen constantly. "Temporary" shooting out of strongly sensitive intuition can best reflect a photographer's skills and professional abilities. In the process of photographic composition, the sketching skills, art cultivation and aesthetic judgement reflected by the aesthetic perspective are beneficial to the variation of scenes and to the highlighting of visual centers and subjects of works. If a photographer who is good at momentary shooting has the superpower of composing from the aesthetic perspective, he will be more likely to succeed.

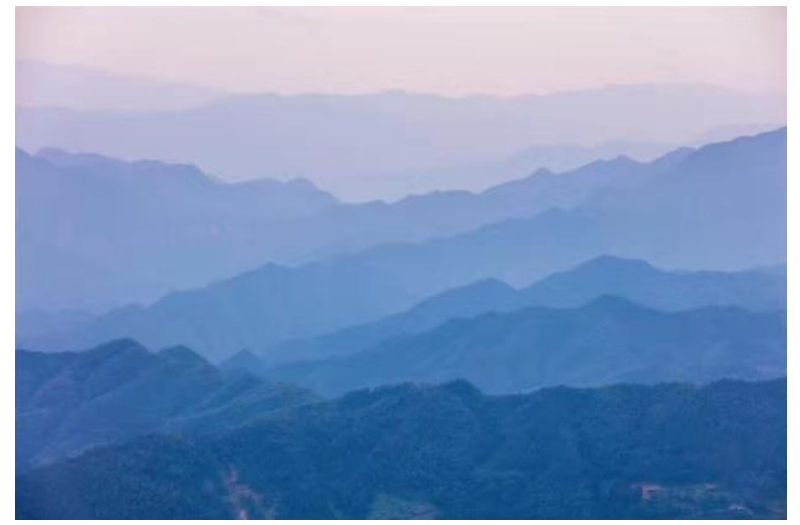

Fig. 5. View 


\section{THE AESTHETIC PERSPECTIVE REFLECTED BY THE HOLISTIC STRUCTURAL ANALYSIS OF PHOTOGRAPHIC COMPOSITION}

\section{A. The structure of photographic composition is beneficial to the forming of people's visual perception of pictures}

The holistic structure of photographic composition is the basic requirement to create a great work. Only by exploring it can one form clear visual consciousness. When one shoot pictures, he organize the holistic structure according to the scene and stimulate our brains through his vision. The scene will be transformed into a 3-D graph in one's brain. Then, with the graph as a reference, one great photo will be shot when he press the shutter. The visual integrity can reflect people's perception of objects, which is the fusion of eyes and the brain, not just the scenes directly perceived by eyes. However, if the structure of a scene is disheveled, the holistic structural analysis of photographic composition can not be conducted and the aesthetic perspective reflected by it can not be found. For example, the scene of the picture on the right is disheveled, which records the spectacle when students enter the examination hall of College English Test (CET) in succession. In the composition of this picture, you can not find the centre. There is a holistic scene in this picture, but there is a lack of uniqueness. Therefore, the aesthetic perspective reflected by the holistic structural analysis of photographic composition is beneficial to the forming of people's visual perception of pictures and can draw people's more attention to the scenes of pictures.

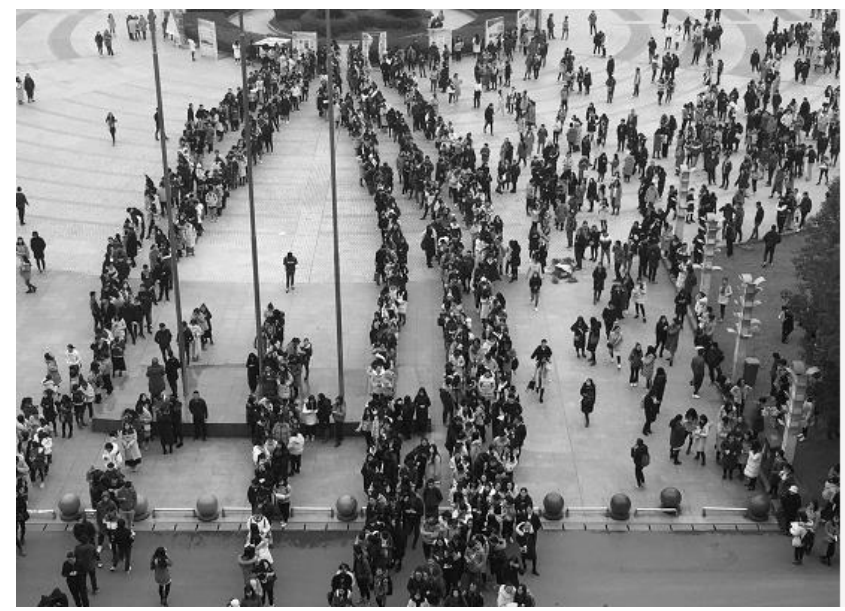

Fig. 6. Outside the examination hall of CET in Hunan University of Humanities Science and Technology

\section{B. The holistic structure of photographic composition can better highlight subjects}

The unique future of photography is that it is on-spot. It will record both useful and useless objects. Photographers can not avoid objects they are not interested in. So when they take pictures, they can only choose the gradations and scenes according to the key points of subjects and present them through valuable visual elements and information. Meanwhile, photographic composition is also affected by visualpsychological factors. Visual stimulus reflected by different composition is also different. Thus, many methods need to be adopted to realize the holistic principles of photographic composition. The first is the principle of closeness, which means regarding closer objects as an organic entirety. The second is the principle of similarity, which means regarding objects of the same lightness, saturation and color as an entirety. The third is the principle of total form, which is fragmented, means integrating incomplete, separated and discrete elements into an entirety with a consecutive shape, then concretizing and deepening it. Only through various methods of photographic composition can subjectivity be better highlighted.

\section{CONCLUSION}

With the advancement of the society and the development of science and technology, the form of photographic art has evolved from traditional film photography to digital photography, which is different from both social and natural beauty. What it presents is the formal beauty of photographic art. Shooting with digital cameras and camera phones, and processing pictures with computers has become a fashion. As more and more people are actively joining photographing, the principle of formal beauty and the exploration for the aesthetic perspective of the art of photographic composition in photography plays an important role in the era of mass photography. Therefore, to create a great work, one need to master photographic composition and guide his artistic creation from the artistic perspective.

\section{REFERENCES}

[1] Zhang, Jinhe. The Charm of Photography and Photographic Composition. Shanghai: Fudan University Press, 2007.

[2] Li, Qiang. The Composition of Scenes. Guilin: Guangxi Normal University Press, 2004.

[3] Arnheim, Rudolf. Visual Thinking. Beijing: Guangming Daily Press, 2000 .

[4] Li, Xingguo. Art of Photographic Composition. Beijing: Beijing Normal University Press, 1998.

[5] Gombrich, E. H. The Sense of Order: A Study in the Psychology of Decorative Art. Hangzhou: Zhejiang Photography Press, 1987.

[6] Zakia, Richard D. Photographic Composition: A Visual Guide. Beijing: Post \& Telecom Press, 2012.

[7] Bao, Wencan. A Guide to Digital Photography. Beijing: JinDun Publishing House, 2004.

[8] Yu, Zhaoxia. Zhang, Huabin. "A Talk about Composition of Photographic Art." Journal of Weifang Engineering Vocational College, 1996. 